\title{
Biometria e germinação de sementes de Macrolobium acaciifolium (Benth.) Benth. de várzea e igapó da Amazônia Central
}

\author{
Lucélia Rodrigues Santos ${ }^{1, *}$ (i), Marilene de Campos Almeida ${ }^{2}$, Florian Wittmann ${ }^{3}$ (B)
}

\author{
'Parte da dissertação do primeiro autor, Programa de pós-graduação em Botânica, Instituto Naciona \\ de Pesquisas da Amazônia, Av. André Araújo, 2936, Petrópolis, CEP 69066-375, Manaus, AM, Brasil \\ *Autor para correspondência: santos.luceliarodrigues@gmail.com \\ ${ }^{2}$ Universidade Federal do Acre, Parque Zoobotânico, BR-364 km 04, Distrito Industrial, CEP 69920-900, Rio Branco, AC, Brasil \\ ${ }^{3}$ Departament of Wetland Ecology, Institute of Geography and Geoecology, Karlsruhe Institute \\ of Technology, Kaiserstr. 12, 76131, Karlsruhe, Baden-Wuerttemberg, Gemany
}

\begin{abstract}
RESUMO - Este estudo objetivou a análise morfométrica de sementes de Macrolobium acaciifolium oriundas de ambientes de várzea e igapó amazônicos, bem como o efeito dos substratos dessas áreas na germinação e formação de plântulas da espécie. Foi realizada a análise biométrica de 200 sementes de M. acaciifolium provenientes de populações de ambos ambientes da Amazônia Central. Em casa de vegetação foi analisada a germinação das sementes sob seu solo de origem e sob vermiculita. As sementes oriundas de igapó apresentaram maiores médias de peso e espessura em comparação com as sementes de várzea. A porcentagem de germinação das sementes dos dois ambientes foi semelhante, mas a velocidade foi superior para as sementes de igapó, independente do substrato. As sementes de igapó são maiores que as sementes de várzea e por possuírem mais reservas, são capazes de produzir plântulas mais vigorosas, independente das condições físicas do substrato.
\end{abstract}

Palavras-chave: biomassa, florestas alagáveis, propagação de espécies florestais

\begin{abstract}
This study focuses on the morphometric analysis of seeds of Macrolobium acaciifolium from environments of Amazonian floodplains and igapó, as well as the effect of the substrates of these areas on the germination and seedling formation of the species. A biometric analysis of 200 M. acaciifolium seeds from populations of both Central Amazon environments was performed. In greenhouse, germination of seeds under their soil of origin and under vermiculite was analyzed. The seeds from igapó presented higher mean weight and thickness compared to the floodplain seeds, which, on occasion, presented higher averages of length and width. The seed germination percentage of both environments was similar, but the speed was higher for the igapó seeds, regardless of the substrate. The igapó seeds are larger than the floodplain seeds and, because they have more reserves, they are able to produce more vigorous seedlings, regardless the physical conditions of the substrate.
\end{abstract}

Keywords: biomass, flooded forests, propagation of forest species

\section{INTRODUÇÃO}

Macrolobium acaciifolium (Benth.) Benth. é uma Fabaceae (Caesalpinoideae), popularmente conhecida como arapari, com hábito arbóreo e de ocorrência tanto na terra firme quanto em baixas elevações nas áreas de várzea e de igapó da Amazônia (Stropp et al. 2011). A espécie possui relevante importância econômica, ecológica e medicinal. $\mathrm{O}$ fato de desenvolver anéis de crescimento bastante distintos e alcançar idades elevadas em torno de 500 anos, faz do M. acaciifolium uma espécie adequada a estudos de dendrocronologia (Schöngart et al. 2005), suas cascas e folhas possuem propriedades anti-inflamatórias e cicatrizantes (Hajdu \& Hohmann 2011). A madeira possui densidade aproximada de $0,49 \mathrm{~g} / \mathrm{cm}^{3}$ a $0,07 \mathrm{~g} /$ $\mathrm{cm}^{3}$ apresentando potencial de utilização em movelaria, fabricação de compensados e na construção civil (Wittmann et al. 2010 a).
Os frutos da espécie são do tipo legume, indeiscentes, hidrocóricos e podem germinar depois de flutuar por até 36 dias (Barnett et al. 2015). As sementes são recalcitrantes apresentando germinação do tipo fanerocotiledonar hipógea com cotilédones armazenadores (Maia et al. 2005). Segundo Feitoza et al. (2014), cada fruto possui apenas uma semente, mas neste trabalho durante a abertura dos frutos foram encontrados alguns contendo duas sementes. Em áreas inundadas os frutos de arapari fazem parte da alimentação de peixes, entre eles o tambaqui (Colossoma macroporum), espécie bastante consumida na Amazônia (Silva et al. 2003).

Os solos das florestas alagáveis onde o M. acaciifolium ocorre possuem aspectos bem distintos devido ao tipo de sedimentos que recebem. Características físico-químicas da água como $\mathrm{pH}$, quantidades de nutrientes e tamanho de partículas variam consideravelmente e se refletem nos solos desses ambientes (Wittmann et al. 2006). As várzeas estão 
sujeitas à inundação periódica dos rios Amazonas, Purus e Madeira de águas barrentas com alta carga de sedimentos de erosões recentes provenientes dos Andes e encostas pré-andinas, possuindo $\mathrm{pH}$ próximo da neutralidade $\mathrm{e}$ grande quantidade de minerais dissolvidos, formando solos nutricionalmente ricos (Pereira et al. 2009). Já os igapós são inundados por rios de água preta com $\mathrm{pH}$ ácido, em razão das altas concentrações de substâncias orgânicas dissolvidas, principalmente sob a forma de ácidos húmicos e fúlvicos provenientes da decomposição da matéria orgânica da floresta (Bleich et al. 2014). Essas águas contêm poucos nutrientes por carrearem sedimentos pobres em minerais provenientes de rochas bastante erodidas dos antigos escudos das Guianas e do Brasil Central, por consequência, o solo nessas áreas apresenta menor quantidade de nutrientes minerais em comparação com o solo de várzea (Wittmann et al. 2010b).

Alguns autores têm afirmado que maior disponibilidade de nutrientes dos ambientes de várzea possibilita que algumas espécies tenham mais sucesso competitivo se comparadas a outras provenientes de ambiente de igapó onde a disponibilidade nutricional é mais baixa (Ferreira et al. 2005). Esses estudos mostram que os aspectos fisiológicos e morfológicos de espécies que colonizam as planícies inundáveis podem mudar de acordo com o tipo de área onde se encontram. Kitajima \& Fenner (2007), verificaram que espécies de igapó geralmente tendem a apresentar sementes maiores e mais pesadas do que espécies de várzea. Segundo os autores, as características funcionais das sementes como germinação, massa e teor de nutrientes podem apresentar variações em ambientes que possuem características contrastantes, indicando possíveis adaptações a um determinado nicho.

Schöngart et al. (2005) observaram que o incremento radial em árvores de $M$. acaciifolium de populações de várzea era superior ao incremento radial de indivíduos da mesma espécie em populações de igapó, a despeito destes últimos apresentaram idades mais elevadas (idade máxima de 500 anos em indivíduos de igapó e 200 anos em indivíduos de várzea). No entanto, nenhum estudo comparativo com foco no desenvolvimento inicial da espécie ainda havia sido realizado.

Considerando a importância ecológica, econômica, medicinal e científica da espécie $M$. acaciifolium, este estudo objetivou avaliar se as condições nutricionais e físicas dos solos de várzea e igapó interferem na morfometria, no processo de germinação de sementes e na biomassa de plântulas desses dois ambientes, cujas informações servirão para auxiliar no entendimento do estabelecimento da espécie nessas áreas.

\section{MATERIAL E MÉTODOS}

Os frutos de Macrolobium acaciifolium de várzea foram coletados na região da Ilha da Marchantaria $\left(03^{\circ}\right.$ $13^{\prime} \mathrm{S} 59^{\circ} 58^{\prime} \mathrm{W}$ ) e imediações - em áreas que sofrem inundação periódica pelas águas do Rio Solimões. Os frutos de populações de igapó foram coletados próximo ao igarapé Tarumã-mirim ( $\left.3^{\circ} 01^{\prime} 38^{\prime \prime} \mathrm{S} 60^{\circ} 10^{\prime \prime} 45^{\prime} \mathrm{W}\right)$ que faz parte da bacia do rio Negro, situado a noroeste da cidade de Manaus. Os frutos foram coletados entre os meses de abril e maio de 2015. As árvores matrizes tiveram os galhos balançados, os frutos maduros desprenderam-se facilmente e caíram na água onde efetuou-se a coleta.

Após coletados, os frutos foram acondicionados em sacos de ráfia e levados para o Instituto Nacional de Pesquisas da Amazônia, onde efetuou-se a retirada das sementes manualmente com auxílio de uma faca. A seleção de sementes seguiu critérios visuais, sendo consideradas saudáveis aquelas sem sinais de fungos, nematoides ou ataque de insetos (Brasil, 2009), passando em seguida por desinfecção por imersão em solução de hipoclorito de sódio a $10 \%$ por dez minutos (Martins-Corder \& Borges-Júnior 1999) e lavadas em água corrente.

As dimensões e massa das sementes foram determinadas para duas subamostras de 100 sementes (Cruz \& Carvalho 2002, Zuffo et al. 2017), sendo 100 sementes de várzea e 100 sementes de igapó. As medidas de largura (mm), espessura $(\mathrm{mm})$ e comprimento $(\mathrm{mm})$ foram aferidas por meio de paquímetro digital (modelo Kingtools) e a massa fresca em gramas obtida com balança analítica (modelo Bel Mark 210A) com precisão de quatro casas decimais.

As sementes foram postas para germinar em bandejas plásticas de $20 \mathrm{~cm} \times 60 \mathrm{~cm}$, em profundidade de semeadura de aproximadamente $5 \mathrm{~cm}$, os substratos utilizados foram solo de origem (coletados em locais próximos às matrizes) ou vermiculita, totalizando quatro tratamentos de cinco repetições de 20 sementes: $M$. acaciifolium de igapó em solo de igapó; M. acaciifolium de igapó em vermiculita; $\mathrm{M}$. acaciifolium de várzea em solo de várzea; e $M$. acaciifolium em vermiculita. As bandejas foram dispostas em bancadas em casa de vegetação telada. As regas foram feitas com água de poço artesiano apenas para manter a umidade dos substratos devido às altas temperaturas na cidade de Manaus, a frequência variava conforme a necessidade de umedecimento observada diariamente.

A coleta para análise do solo utilizado como substrato também foi realizada em áreas próximas ao local onde se encontravam as árvores matrizes, uma vez que durante este período a área onde estas estavam situadas ainda se encontrava inundada. Para compor as amostras a serem analisadas foram coletadas 10 subamostras de solo a 30 $\mathrm{cm}$ de profundidade em cada ambiente (várzea e igapó), a profundidade da coleta seguiu a recomendação de Furch (1997) para solos alagáveis. As análises granulométrica e química foram realizadas pelo laboratório de Análise de Solos e de Plantas-LASP Embrapa Manaus.

O experimento teve início no dia dois de junho de 2015 sendo encerrado dia três de agosto do mesmo ano, quando houve a estabilização da germinação, considerando-se como germinada a semente que apresentou emergência do epicótilo. A porcentagem, o tempo médio e a frequência germinativa foram calculados através das fórmulas propostas por Labouriau e Agudo (1987). O índice de 
velocidade de germinação foi calculado de acordo com Maguire (1962).

Para a medição do crescimento das plântulas de $M$. acaciifolium retirou-se aleatoriamente de cada tratamento 20 indivíduos com altura mínima de $30 \mathrm{~cm}$ cada, sendo a parte aérea separada da raiz com tesoura, e as duas partes medidas individualmente com trena. A medida da parte aérea foi tomada desde a gema apical até o colo e a medida das raízes do final do colo até a extremidade final da raiz primária, e os resultados expressos em centímetros (Labouriau \& Agudo 1987).

A determinação da biomassa seca foi efetuada após realizar as medições das partes das plantas, tendo estas sido acondicionadas em sacos de papel do tipo kraft e levadas para a estufa a $80^{\circ} \mathrm{C}$ até atingirem peso constante (Alves et al. 2012). Após a secagem o material foi pesado em balança analítica (Bel Mark 210A) com precisão de quatro casas decimais e os resultados expressos em gramas.

O delineamento experimental utilizado foi o inteiramente casualizado. Os dados foram submetidos ao teste de normalidade de Kolmogorov-Smirnov, posteriormente realizou-se a análise de variância e a comparação de médias pelo teste de Tukey a $5 \%$ de probabilidade. O programa utilizado para as análises foi o Assistat 7.7 Beta (Silva \& Azevedo 2016).

\section{RESULTADOS E DISCUSSÃO}

A análise dos solos coletados nos dois ambientes revelou que o solo de igapó possui mais matéria orgânica do que o solo de várzea, no entanto menos nutrientes. A fração de areia grossa no solo de igapó é expressivamente maior do que a encontrada no solo de várzea (Tab. 1). Estes resultados corroboram o postulado por Furch (1997) que afirma que há maior disponibilidade nutricional em solos de várzea e maior porosidade nos solos de igapó em decorrência da textura arenosa.

As sementes de $M$. acaciifolium provenientes de populações do ambiente de igapó apresentam maiores médias de peso $(5,9 \mathrm{~g})$ e espessura $(7,5 \mathrm{~mm})$ do que as sementes de populações de várzea, com peso $4,7 \mathrm{~g} \mathrm{e} 6,4 \mathrm{~mm}$ de espessura (Tab. 2). De acordo com Parolin (2000) a quantidade de nutrientes dos solos em florestas alagáveis na Amazônia Central atua na formação de sementes fazendo com que estas quando oriundas de solos pobres possuam mais reservas nutricionais do que sementes onde a disponibilidade nutricional é mais elevada. Isto possibilita o fornecimento de mais nutrientes para as plântulas na tentativa de promover seu estabelecimento no local.

As médias ( $\mathrm{mm}$ ) de comprimento e largura das sementes de várzea 38,3 e 32,1, e das sementes de igapó 39,1 e 31,1, respectivamente. O Coeficiente de Variação alcançou valores entre $11,4 \%$ a $27,5 \%$, indicando que a espécie apresenta ampla variação fenotípica. As médias de tamanho das sementes de $M$. acaciifolium foram próximas às médias registradas por Feitoza et al. (2014), que em estudo realizado com 50 sementes coletadas na floresta de várzea da ilha do Combu em Belém, encontraram médias de comprimento para sementes desta espécie variando de 23,25 e $32,28 \mathrm{~mm}$, largura de 29,66 a 40,44 mm e espessura de 4,95 a $7,18 \mathrm{~mm}$.

Tabela 1. Análises química e granulométrica do solo. $\mathrm{SB}=$ soma de bases trocáveis: $\mathrm{CTC}=$ Capacidade de troca catiônica efetiva; $\mathrm{V}=$ índice de saturação por bases; $\mathrm{m}$ = índice de saturação por alumínio; M. O.= matéria orgânica.

\begin{tabular}{|c|c|c|c|c|c|c|c|c|c|c|c|c|c|c|c|c|}
\hline \multirow[t]{2}{*}{$\begin{array}{l}\text { Substrato de } \\
\text { Origem }\end{array}$} & \multicolumn{16}{|c|}{ Complexo sortivo das amostras } \\
\hline & $\mathrm{C}$ & M.O. & $\mathrm{P}$ & $\mathrm{K}^{+}$ & $\mathrm{Na}^{+}$ & $\mathrm{Fe}$ & $\mathrm{Zn}$ & $\mathrm{Mn}$ & $\mathrm{Cu}$ & $\mathrm{Mg}^{2+}$ & $\mathrm{Ca}^{+}$ & SB & $\mathrm{Al}^{3+}$ & CTC & $\mathrm{V}$ & $\mathrm{m}$ \\
\hline & \multicolumn{2}{|c|}{--- $(\mathrm{g} / \mathrm{kg})$--- } & \multicolumn{7}{|c|}{ 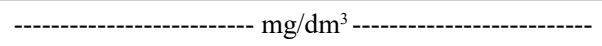 } & \multicolumn{5}{|c|}{ - - } & \multicolumn{2}{|c|}{------ \% ------ } \\
\hline Várzea & 14,8 & 5,08 & 120 & 58 & 19 & 406 & 5,1 & 128 & 3,71 & 1,24 & 4,76 & 6,23 & 0,0 & 6,89 & 90,42 & 0,0 \\
\hline \multirow[t]{3}{*}{ Igapó } & 2,95 & 23,53 & 4 & 12 & 3 & 464 & 0,76 & 0,50 & 0,66 & 0,06 & 0,06 & 0,16 & 1,77 & 3,99 & 4,10 & 91,53 \\
\hline & \multirow{2}{*}{\multicolumn{2}{|c|}{$\begin{array}{c}\mathrm{pH} \\
\left(\mathrm{H}_{2} \mathrm{O}\right)\end{array}$}} & \multicolumn{14}{|c|}{ Análise granulométrica $(\mathrm{g} / \mathrm{kg})$} \\
\hline & & & \multicolumn{3}{|c|}{$\begin{array}{c}\text { Areia grossa } \\
2,00-0,20(\mathrm{~mm})\end{array}$} & \multicolumn{3}{|c|}{$\begin{array}{c}\text { Areia Fina } \\
0,20-0,05(\mathrm{~mm})\end{array}$} & \multicolumn{3}{|c|}{$\begin{array}{c}\text { Silte } \\
0,05-0,002(\mathrm{~mm})\end{array}$} & \multicolumn{3}{|c|}{$\begin{array}{c}\text { Argila } \\
<0,002(\mathrm{~mm})\end{array}$} & \multicolumn{2}{|c|}{$\begin{array}{c}\text { Relação } \\
\text { Silte/Argila }\end{array}$} \\
\hline Várzea & \multicolumn{2}{|c|}{4,16} & \multicolumn{3}{|c|}{10,87} & \multicolumn{3}{|c|}{651,60} & \multicolumn{3}{|c|}{171,95} & \multicolumn{3}{|c|}{188,5} & \multicolumn{2}{|c|}{0,92} \\
\hline Igapó & \multicolumn{2}{|c|}{4,69} & \multicolumn{3}{|c|}{632,59} & \multicolumn{3}{|c|}{143,97} & \multicolumn{3}{|c|}{149,03} & \multicolumn{3}{|c|}{51,50} & \multicolumn{2}{|c|}{2,89} \\
\hline
\end{tabular}

Tabela 2. Resumo da análise de variância para o comprimento ( $\mathrm{mm})$, peso (g), largura ( $\mathrm{mm}$ ) e espessura (mm) das sementes de Macrolobium acaciifolium oriundas de várzea e igapó da Amazônia Central.

\begin{tabular}{lcccc}
\hline Ambientes & Peso $(\mathrm{g})$ & Comprimento $(\mathrm{mm})$ & Largura $(\mathrm{mm})$ & Espessura $(\mathrm{mm})$ \\
\hline \multirow{2}{*}{ Várzea } & $4,7 \pm 1,6 \mathrm{~B}$ & $38,3 \pm 5,8 \mathrm{~A}$ & $32,1 \pm 3,6 \mathrm{~A}$ & $6,4 \pm 1,3 \mathrm{~B}$ \\
& $(\mathrm{CV}=34,2)$ & $(\mathrm{CV}=15,3)$ & $(\mathrm{CV}=11,4)$ & $(\mathrm{CV}=21,11)$ \\
\multirow{2}{*}{ Igapó } & $5,9 \pm 1,6 \mathrm{~A}$ & $39,1 \pm 4,8 \mathrm{~A}$ & $31,1 \pm 4,6 \mathrm{~A}$ & $7,5 \pm 1,6 \mathrm{~A}$ \\
& $(\mathrm{CV}=27,5)$ & $(\mathrm{CV}=12,4)$ & $(\mathrm{CV}=14,9)$ & $(\mathrm{CV}=21,9)$ \\
\hline
\end{tabular}

Médias seguidas pela mesma letra na coluna não diferem entre si ao nível de 5\% de significância pelo Teste de Tukey. Média \pm desvio padrão. CV= Coeficiente de Variação, $n=100$. 
O início da germinação das sementes de M. acaciifolium se deu no sétimo dia, estendendo-se até o $52^{\circ}$ dia. A rápida germinação observada se deve à recalcitrância das sementes da espécie, característica associada à sobrevivência da mesma. A germinação rápida em decorrência do alto teor de água previne a perda de viabilidade da semente por exposição ao ambiente seco, o que coincide com o período de redução das chuvas na região amazônica (Parolin \& Wittmann, 2010), indicando adaptabilidade da espécie ao clima local.

As médias de germinação das sementes de $M$. acaciifolium variaram de 56 a $85 \%$, não diferindo estatisticamente entre elas, tanto em seu solo de origem quanto em vermiculita. (Tab. 3). Essa média foi bem próxima da encontrada por Maia et al. (2005), com $90 \%$ de germinação para um lote de 500 sementes de $M$. acaciifolium coletadas em área de várzea do Rio Solimões, utilizando-se areia lavada como substrato.

Quanto ao índice de velocidade de germinação (IVG), verificou-se que as sementes de várzea postas para germinar em solo de origem apresentaram médias significativamente inferiores a vermiculita (Tab. 3), o que sugere que substratos mais porosos favorecem o processo germinativo da semente desta espécie.

Na Fig. 1 observam-se vários polígonos de frequência relativa da germinação de sementes de $M$. acaciifolium, nos quais as distribuições de frequência demonstram caráter polimodal para todos os lotes de sementes testados. Observou-se que os intervalos entre o registro das germinações foi mais longo nas sementes de várzea semeadas em solo de origem (Fig. 1A) do que nas sementes coletadas na várzea e semeadas em vermiculita (Fig. 1B) e nas coletas em igapó e semeadas em solo de igapó e em vermiculita (Figs.1 C, D).

As sementes oriundas de igapó apresentaram germinação mais distribuída ao longo do tempo de duração do experimento. A menor densidade encontrada no solo de igapó pode ter contribuído para esse resultado, por mais argiloso, o solo de várzea tende a formar uma crosta mais endurecida o que dificulta a emergência das plântulas,

Tabela 3. Médias de porcentagem e velocidade de germinação de sementes de Macrolobium acaciifolium oriundas de várzea e igapó da Amazônia Central, postas para germinar em diferentes substratos.

\begin{tabular}{lccc}
\hline Origem das sementes & Tipo de substrato & Germinação (\%) & IVG \\
\hline \multirow{2}{*}{ Várzea } & Solo de várzea & $56 \mathrm{~A}$ & $1,39 \mathrm{~B}$ \\
& Vermiculita & $83 \mathrm{~A}$ & $1,54 \mathrm{~A}$ \\
\multirow{2}{*}{ Igapó } & Solo de igapó & $68 \mathrm{~A}$ & $1,57 \mathrm{~A}$ \\
& Vermiculita & $85 \mathrm{~A}$ & $1,57 \mathrm{~A}$ \\
$\mathrm{CV}(\%)$ & & 25,8 & 13,2 \\
\hline
\end{tabular}

Médias seguidas de mesma letra na coluna não diferem estatisticamente entre si ao nível pelo Teste de Tukey a 5\% de significância. CV= coeficiente de variação. IVG= índice de velocidade de germinação.
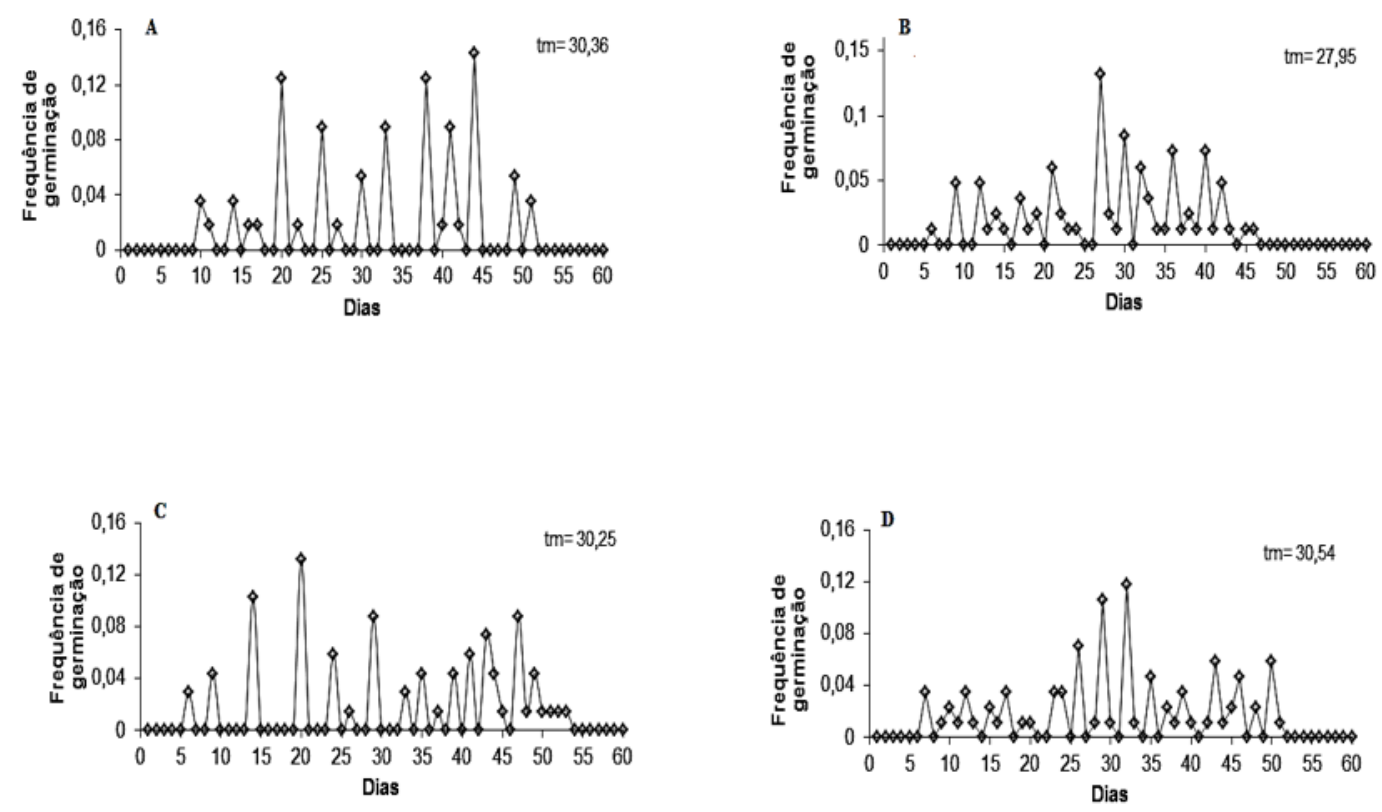

Fig. 1. A-D. Polígonos da frequência relativa da germinação de sementes de Macrolobium acaciifolium oriundas de várzea e igapó da Amazônia Central, em função de diferentes substratos. A. sementes de área de várzea plantadas em solo de várzea; $\mathbf{B}$. sementes de área de várzea plantadas em vermiculita; C. Sementes de área de igapó plantadas em solo do igapó; D. Sementes de área de igapó plantadas em vermiculita. Tm $=$ tempo médio da germinação. 
o que pode explicar o menor IVG registrado durante a germinação das sementes neste substrato.

A análise da biomassa seca apontou diferenças significativas quanto ao peso e comprimento da parte aérea e para o comprimento da raiz das plântulas de $M$. acaciifolium oriundas de várzea e de igapó (Tab. 4).

As plântulas germinadas a partir das sementes coletadas na área de igapó apresentaram médias superiores de peso da parte aérea e comprimento total. $\mathrm{O}$ comprimento da parte aérea foi estatisticamente menor nas plântulas de várzea plantadas em seu solo de origem. Não houve diferença estatística significativa entre as médias de peso das raízes (Tab. 4). Entretanto, observou-se que as raízes das plântulas que se desenvolveram em solo de várzea apesar de mais curtas formavam um emaranhado mais denso, enquanto as raízes das plântulas de igapó se mostravam mais longas e com menos ramificações.

O menor comprimento observado nas raízes das plântulas que se desenvolveram em substrato de várzea pode estar relacionado a mais de um fator, como as plântulas de várzea que se desenvolveram em vermiculita alcançaram médias de comprimento radicular estatisticamente próximas as médias das raízes de plântulas de igapó, exclui-se a possibilidade do menor tamanho de raízes estar ligado à limitação genética. O que nos leva a considerar as limitações e vantagens referentes ao substrato. A ausência da necessidade de investir no crescimento radicular por estarem em um meio mais rico em nutrientes não necessitando expandir tanto a superfície de contato quanto as plântulas em vermiculita e em substrato de igapó, pode ter feito com que as raízes de plântulas em substrato de várzea se desenvolvessem menos em extensão.

De acordo com Ribeiro et al. (2007), a presença de uma rede ideal de poros exerce expressiva influência sobre a fertilidade do solo, afetando as relações entre drenagem, absorção de nutrientes, penetração de raízes, aeração e temperatura, relacionando-se diretamente com o desenvolvimento e produtividade das culturas. Normalmente, o aumento do conteúdo de água no solo reduz o volume de poros ocupados por ar, bem como os canais condutores de ar ocasionando maior retenção de água, ou seja, maior volume de poros preenchidos com água, o que constitui um bloqueio para a passagem de ar, resultando em redução na permeabilidade do solo ao ar (Rodrigues et al., 2011). Negreiros et al. (2004) afirmam que solos com maior aeração distribuem melhor a umidade, como o caso do solo de igapó, proporcionando um maior incremento no diâmetro do coleto das plântulas.

As maiores médias de crescimento aéreo foram observadas nas plântulas oriundas de igapó, mas essas médias não diferiram estatisticamente da média de comprimento encontrada nas plântulas de várzea plantadas em vermiculita. O substrato de igapó é reconhecidamente mais pobre em nutrientes, indicando que para a espécie em estudo, uma taxa mais elevada de nutrientes não significou necessariamente maior incremento de biomassa na parte aérea nesta fase.

Também foi observado que as plantas jovens de M. acaciifolium quando semeadas em vermiculita, um substrato inerte, apresentaram maior média de crescimento do que sementes do mesmo lote que germinaram e se desenvolveram em substrato de várzea. Este fato levanos à hipótese da influência granulométrica do substrato também no desenvolvimento inicial das mudas. De acordo com Alves et al. (2008) os substratos onde se observam os maiores comprimentos das plântulas apresentam requisitos que favoreceram uma rápida e uniforme emergência, como constatado durante o teste de germinação para os substratos de vermiculita e solo de igapó. O desenvolvimento mais uniforme das plântulas de igapó garantiram o maior vigor destas comparadas às plântulas de várzea.

Segundo Suguino et al. (2011), substratos com menor macroporosidade criam condições desfavoráveis para a germinação das sementes, o estabelecimento e o crescimento das mudas germinadas, pois, ao aumentar o número de microporos, diminui-se a aeração no interior do substrato, o que pode explicar o ocorrido com as plântulas que se desenvolveram em solo de várzea. Tanto a vermiculita quanto o substrato de igapó favorecem a aeração, pois são mais porosos do que o substrato de várzea, por este conter mais argila.

O substrato mais compactado reduz o estoque de oxigênio e pode interferir nas trocas gasosas entre a raiz e o meio, limitando a atividade metabólica radicular. Um dos principais hormônios vegetais do crescimento,

Tabela 4. Médias de comprimento e peso de biomassa seca de plântulas de Macrolobium acaciifolium oriundas de sementes de várzea e igapó semeadas em diferentes substratos.

\begin{tabular}{|c|c|c|c|c|c|}
\hline \multirow{3}{*}{$\begin{array}{l}\text { Parâmetros } \\
\text { avaliados }\end{array}$} & \multicolumn{5}{|c|}{ Origem das sementes e substrato } \\
\hline & \multicolumn{2}{|c|}{ Igapó } & \multicolumn{2}{|c|}{ Várzea } & \multirow{2}{*}{$\mathrm{CV}(\%)$} \\
\hline & Solo de igapó & Vermiculita & Solo de várzea & Vermiculita & \\
\hline Peso da raiz (g) & $0,76^{\mathrm{ns}}$ & 0,71 & 0,668 & 0,68 & 20,5 \\
\hline Peso da parte aérea $(\mathrm{g})$ & $2,62 \mathrm{~A}$ & $2,47 \mathrm{~A}$ & $1,72 \mathrm{~B}$ & $2,23 \mathrm{~A}$ & 26,3 \\
\hline Comprimento da raiz $(\mathrm{cm})$ & $18,84 \mathrm{~A}$ & $21,85 \mathrm{~A}$ & $12,99 \mathrm{~B}$ & $20,29 \mathrm{~A}$ & 23,68 \\
\hline $\begin{array}{l}\text { Comprimento da parte } \\
\text { aérea }(\mathrm{cm})\end{array}$ & $52,17 \mathrm{~A}$ & $55,57 \mathrm{~A}$ & $39,95 \mathrm{~B}$ & $49,47 \mathrm{~A}$ & 20,7 \\
\hline
\end{tabular}

Médias seguidas pela mesma letra na linha não diferem estatisticamente entre si ao nível de $5 \%$ de probabilidade pelo teste de Tukey. CV=Coeficiente de Variação. ${ }^{\text {ns }}=$ não significativo. 
a citosina, apesar de ser produzido em outras partes da planta, é fabricado em maior quantidade nas raízes. Limitações no metabolismo radicular podem reduzir a produção de hormônios e se refletir no crescimento do vegetal, limitando-o (Ishaq et al., 2001).

Seriam necessários mais estudos, desta vez no campo da bioquímica para desvendar as estratégias de adaptação de plântulas dessa espécie em várzea e igapó e seus diferentes tipos de substratos para definir até que ponto essas variáveis influenciam em seu desenvolvimento.

Através deste estudo verificou-se que o substrato e a origem das sementes não interferiram na porcentagem de germinação das sementes de Macrolobium acaciifolium. A média de peso das sementes de várzea foi estatisticamente superior à média de peso das sementes de igapó, a espessura as sementes de igapó exibiram maior média.

O índice de velocidade de germinação em solo de várzea mostrou-se inferior aos demais tratamentos, indicando que para essa variável o solo é um fator limitante. As mudas de igapó apresentaram maiores médias de comprimento e peso da parte aérea e comprimento da raiz.

\section{AGRADECIMENTOS}

Ao grupo Mauá/INPA pelo apoio logístico e infraestrutura. Ao barqueiro Mário, aos técnicos Valdeney, Celso e Kelvin pelo auxílio na execução do trabalho de coleta de sementes e solo em campo. À Dra. Astrid Wittmann e ao Dr. Ricardo Marenco pelas contribuições valiosas. Ao Conselho Nacional de Desenvolvimento Científico e Tecnológico pela concessão da bolsa de mestrado.

\section{REFERÊNCIAS}

Alves, E. U., Andrade, L. A., Barros, H. H. A., Gonçalves, E. P., Alves, A. U., Gonçalves, G. S., Oliveira, L. S. B., Cardoso, E. A. 2008. Substratos para testes de emergência de plântulas e vigor de sementes de Erytrina velutina Willd., Fabaceae. Semina 29(1):69-82.

Alves, E., Santos-Moura, S. S., Moura, M. F., Guedes, R. S., Estrela, F. A. F. 2012. Germination and seed vigor Crataeva tapia $\mathrm{L}$. on different substrates and temperatures/ Germinação e vigor de sementes de Crataeva tapia $\mathrm{L}$. em diferentes substratos e temperaturas. Revista Brasileira de Fruticultura 34(4):1208-1215.

Barnett, A., Almeida, T., Andrade, R., Boyle, S., Lima, M. G., Maclarnon, A., Ross, C. Silva, W. S., Spironello, W. R., Ronchi-Teles, B. 2015. Ants in their plants: Pseudomyrmex ants reduce primate, parrot and squirrel predation on Macrolobium acaciifolium (Fabaceae) seeds in Amazonian Brazil. Biological Journal of the Linnean Society 114(2):260-273.

Bleich, M., Piedade, M. T. F., Knopki, P. B., Castro, N. G. D., Jati, S. R., Sousa, R. N. 2014. Influência das condições do hábitat sobre a estrutura de herbáceas aquáticas na região do Lago Catalão, Manaus, AM. Acta Amazonica 44(4):481-490.

Brasil. 2009. Ministério da Agricultura, Pecuária e Abastecimento, Regras para análise de sementes. Brasília. Ministério da Agricultura, Pecuária e Abastecimento. 399 p.

Cruz, E. D. \& Carvalho, J. E. U. 2002. Biometria de frutos e germinaçõ de sementes de Couratari stellata A. C. Smith (Lecythidaceae). Acta Amazonica 33(3):381-388.

Feitoza, G. V., Santos J. U. M., Gurgel, E. S. C., Oliveira, D. M. T. 2014. Morphology of fruits, seeds, seedlings and saplings of three species of Macrolobium Schreb. (Leguminosae, Caesalpinioideae) in the Brazilian Amazon floodplain. Acta Botanica Brasilica 28(3):422-433.
Ferreira, L. V., Almeida, S. S., Amaral, D. D., Parolin, P. 2005. Riqueza e composição de espécies da floresta de igapó e várzea na Estação Científica Ferreira Pena: subsídios para o plano de manejo da Floresta Nacional de Caxiuanã. Pesquisas, Botânica 65:103-116.

Furch, K. 1997. Chemistry of várzea and igapó soils and nutrient inventory of their floodplain forests. In The Central Amazon floodplains. Ecology of a Pulsing System (W. J. Junk ed.). Springer Verlag, Berlin-Heidelberg-New York, p. 47-67.

Hajdu, Z. \& Hohmann, J. 2012. An ethnopharmacological survey of the traditional medicine utilized in the community of Porvenir, Bajo Paraguá Indian Reservation, Bolivia. Journal of Ethnopharmacology 139(3):838-857.

Ishaq, M. Ibrahim, M., Hassan, A., Saeed, A., Lal, R. 2001. Subsoil compaction effects on crops in Punjab, Pakistan: II. Root growth and nutrient uptake of wheat and sorghum. Soil and Tillage Research 60(1):153-161

Kitajima, K. \& Fenner, M. 2007. Seed and Seedling Ecology. In Functional plant ecology 2 (F. Pugnaire, \& F. Valladares, eds.). CRC Press Taylor \& Francis Group, New York, p. 549-580. DOI: 10.5327/ Z1677-606220191576.

Labouriau, L.G. \& Agudo, M. 1987. On the physiology of seeds germination in Salvia hispanica L. I. Temperature effects. Anais da Academia Brasileira de Ciências 59(1): 37-56.

Maguire, J.D. 1962. Speed of germination: aid in selection and evaluation for seedling emergence and vigor. Crop Science 2(2):176-177.

Maia, L .A., Maia, S. \& Parolin, P. 2005. Seedling morphology of non-pioneer trees in Central Amazonian Várzea floodplain forests. Ecotropica 11:1-8.

Martins-Corder, M. P. \& Borges Junior, N. 1999. Desinfestação e quebra de dormência de sementes de Acacia mearnsii De Wild. Ciência Florestal 9(2): 17.

Negreiros, J. R. S., Álvares, V. S., Braga, L. R., Bruckner, C. H. 2004. Diferentes substratos na formação de mudas de maracujazeiroamarelo. Revista Ceres 2(294):245-249.

Parolin, P. 2000. Seed mass in Amazonian floodplain forests with contrasting nutrient supplies. Journal of Tropical Ecology 3(16):417428.

Parolin, P. \& Wittmann, F. K. 2010. Struggle in the flood: tree responses to flooding stress in four tropical floodplain systems. AoB Plants 03:1-19.

Pereira, M. J. R., Marques, J. T., Santana, J. Santos, C. D., Valsecchi, J., Queiroz, H. L. Beja, P., Palmeirim, J. M. 2009. Structuring of Amazonian bat assemblages: the roles off looding patterns and floodwater nutrient load. Journal of Animal Ecology 78:1163-1171.

Ribeiro, K. D., Menezes, S. M., Mesquita, M. G. B. F., Sampaio, F. M. 2007.Propriedades físicas do solo, influenciadas pela distribuição de poros, de seis classes de solos da região de Lavras-MG. Ciência e Agrotecnologia 31(4):1167-1175.

Rodrigues, S., Silva, A. P., Giarola, N. F. B., Rosa, J. A. 2011. Permeabilidade ao ar em Latossolo Vermelho sob diferentes sistemas de manejo. Revista Brasileira de Ciências do Solo 35(1): 105-114.

Schöngart, J., Piedade, M.T.F., Wittmann, F., Junk, W.J., Worbes, M. 2005. Wood growth patterns of Macrolobium acaciifolium (Benth.) (Fabaceae) in Amazonian black-water and white-water floodplain forests. Oecologia 145(3):454-461.

Silva, F. A. S. \& Azevedo, C. A.V. 2016. The Assistat Software Version 7.7 and its use in the analysis of experimental data. Journal of Agriculture Research 11(39):3733-3740.

Silva, J. A. M., Pereira-Filho, M. \& Oliveira-Pereira, M. I. 2003. Valor nutricional e energético de espécies vegetais importantes na alimentação do tambaqui. Acta Amazonica 33(4): 687-699.

Suguino, E., Martins, A.N., Minami, K., Narita, N., Perdoná, M. 2011. Efeito da porosidade do substrato casca de pinus no desenvolvimento de mudas de grumixameira. Revista Brasileira de Fruticultura (33) nesp.1: 643-648.

Stropp, J., Van Der Sleen, P., Assunção, P. A., Silva, A. L., Ter Steege, H. 2011. Tree communities of white-sand and terra-firme forests of the upper Rio Negro. Acta Amazonica 41(4):521-544.

Wittmann, F., Schöngart, J., Brito, J.M., Oliveira Wittmann, A., Piedade, M.T.F., Parolin, P., Junk, W.J., Guillaumet, J.L. 2010a. Manual of trees from Central Amazonian várzea floodplains: taxonomy, ecology, and use - Manual de árvores de várzea da Amazônia Central: taxonomia, 
ecologia e uso. Instituto Nacional de Pesquisas da Amazônia, Manaus, $298 \mathrm{p}$.

Wittmann, F., Schöngart, J., Junk, W.J. 2010b. Phytogeography, species diversity, community structure and dynamics of central amazonian floodplain forests. In Amazonian Floodplain Forests: ecophysiology, biodiversity and sustainable management (W. J. Junk, M. T. Piedade, F. Wittmann, J. Schöngart \& P. Parolin, eds.). Springer Verlag, Berlin, p. 61-102.
Wittmann, F.; Schöngart, J; Montero, J. C., Motzer, T., Junk, W. J., Piedade, M. T. F., Queiroz, H. L.; Worbes, M. 2006. Tree species composition and diversity gradients in white-water forests across the Amazon Basin. Journal of Biogeography 33:1334-1347.

Zuffo, A. M. Steiner, F.; Zoz, T.; Zuffo Júnior, J. M.; Douradinho, G. Z.; Oliveira, C. P.; Bortolazzo, G. 2017. Atributos biométricos de frutos e sementes de Peltophorum dubium (Spreng.) Taub. Revista de Ciências Agrárias 40(31):61-68. 